
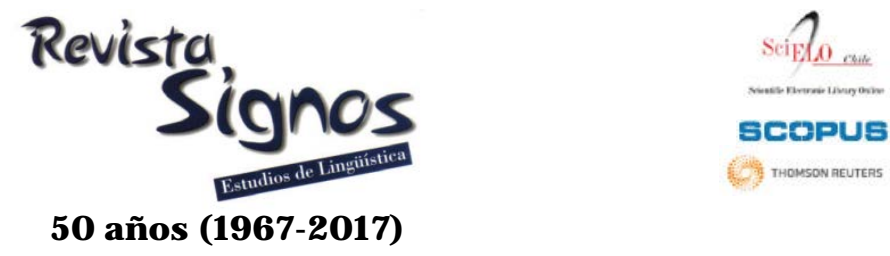

\title{
Expresiones de obligación y función directiva en editoriales de revistas científicas
}

\section{Obligation expressions and directive speech acts in scientific journal editorials}

\author{
Susana Gallardo \\ UNIVERSIDAD DE BUENOS AIRES \\ ARGENTINA \\ sgallardo@de.fcen.uba.ar
}

Recibido: 28/III/2015 / Aceptado: 18/IV/2016

\section{Resumen}

El objetivo del trabajo es determinar criterios para distinguir entre expresiones de obligación con propósito prescriptivo (recomendaciones o sugerencias) y aquellas que podrían tener otras funciones. Para ello, se analizan las expresiones de obligación en un corpus de editoriales de tres revistas científicas de la Argentina. En el marco de los estudios de lenguas para propósitos específicos y los trabajos pragmático-semánticos sobre la estructura accional, se analiza la estructura retórica de los textos y la estructura ilocutiva de los segmentos textuales en que aparecen las expresiones de obligación. Se observa que las expresiones de obligación realizan dos tipos de actos de habla directivos: los prescriptivos, que proponen acciones para ser realizadas por los destinatarios, y los metadiscursivos, que tienen la función de destacar información relevante. Se observan diferencias entre ambos tipos de directivos, principalmente en relación con la función en la estructura ilocutiva. Se observa que una expresión de obligación tiene función prescriptiva si la ilocución directiva es dominante en un segmento textual. En cambio, si la expresión de obligación funciona como apoyo de una dominante asertiva, su valor prescriptivo aparece en segundo plano. El análisis de la estructura ilocutiva puede ser un criterio para establecer distinciones.

Palabras Clave: Discurso científico, género editorial, modalidad deóntica, estructura ilocutiva, función directiva. 


\begin{abstract}
This paper aims at distinguishing between obligation expressions with prescriptive functions (recommendations and suggestions) and obligation expressions with a different function. We focus on deontic modality expressions in a corpus of three scientific journals of Argentina, drawing on studies of languages for specific purposes, and linguistic analysis of rhetorical and illocutionary patterns. We examine illocutionary patterns of rhetorical moves in which those expressions appear. We observed two types of directives: prescriptive ones, which propose activities to the audience, and metadiscursive directives, which aim at highlighting relevant information. These two directives present several differences, especially, in the illocutionary structure. Prescriptive directives constitute the main illocution in the illocutionary pattern, while metadiscursive directives constitute a supportive function. The analysis of illocutionary structure may be set as a criteria for establishing distinctions.
\end{abstract}

Key Words: Scientific discourse, editorial, deontic modality, illocutionary structure, directive function.

\title{
INTRODUCCIÓN
}

Entre la variedad de géneros que componen el discurso científico-académico, el editorial de revistas científicas especializadas es uno de los menos explorados (SalagerMeyer, 2002; Romanos de Tiratel, 2002; Giannoni, 2006; Briceño Velazco, 2014; Sabaj \& Gonzalez, 2013). De acuerdo con Sabaj y González (2013), este género no constituye una entidad homogénea, sino que es multifuncional y cumple con distintos propósitos comunicativos en la comunidad discursiva en la que circula; el principal es "emitir una opinión, expresar un posicionamiento sobre un tema específico" (Sabaj \& González, 2013: 76). Otros editoriales pueden responder al propósito de informar sobre eventos científicos u homenajear a alguna personalidad del área. En particular, respecto de las revistas médicas, Salager-Meyer (2002) señala que los editoriales cumplen un rol central en la comunidad discursiva pues no solo asisten a los lectores a comprender e interpretar los resultados de los estudios clínicos sino que también ayudan a obtener una mayor comprensión de temas éticos vinculados a la práctica médica. Esta implicancia ética también fue destacada por Giannoni (2006). Los autores de los editoriales son especialistas en la materia que tratan (Romanos de Tiratel, 2002), y “juegan el rol de un autor experto, seguro de sí mismo, orientador en las decisiones, con un estatus bien establecido y asignado por la comunidad de pertenencia" (Salager-Meyer, 2002: 74).

Un rasgo característico de los editoriales, tanto en el contexto periodístico como en las revistas especializadas, es la presencia de expresiones con significado de obligación, lo cual podría indicar el compromiso del autor y su intención persuasiva (SalagerMeyer, 2002). No obstante, no todas estas expresiones poseen una función prescriptiva, es decir, no todas proponen acciones a ser realizadas por el destinatario. 
Al respecto, Bolívar (1994) ha señalado que, si bien las expresiones de obligación pueden estar diseminadas a lo largo de los textos, solo las que aparecen en segmentos evaluativos son las que tienen la función de proponer cursos de acción deseables.

El objetivo de este artículo es determinar criterios para distinguir entre aquellas construcciones que expresan actos de habla directivos con un claro propósito prescriptivo (recomendaciones o sugerencias) y aquellas expresiones de obligación que podrían tener otras funciones. En un corpus de editoriales de revistas científicas especializadas consideramos, por un lado, la estructura retórica de los textos, con el fin de determinar en qué segmentos textuales aparecen las expresiones de obligación y, por el otro, nos centramos en la estructura ilocutiva del segmento en que se inserta la expresión en cuestión. La hipótesis es que las expresiones de obligación poseen valor prescriptivo cuando, dentro de una jerarquía ilocutiva, realizan una ilocución dominante, pero si esas expresiones funcionan como apoyo de otras ilocuciones, el valor prescriptivo pasaría a un segundo plano.

\section{Marco teórico}

Con el fin de contribuir a la caracterización del editorial de revistas especializadas, aquí realizamos, por un lado, un abordaje del texto desde una perspectiva funcional, considerando los patrones retóricos globales (Swales, 1990; Nwogu 1997; Hyland, 1998, 2002, 2005). Por el otro, adoptamos un enfoque pragmático-semántico, al centrarnos en los actos de habla directivos formulados en los textos y en la estructura accional en que se insertan (Brandt \& Rosengren, 1992).

Desde un enfoque funcional, numerosos trabajos se centraron en el discurso científico-académico y, en particular, en el artículo de investigación. En tal sentido, fueron centrales los aportes de Swales (1990) y su concepto de 'movida retórica' como unidad funcional y proposicional, que posee una fuerza ilocutiva, un contenido proposicional y determinados rasgos léxico-gramaticales característicos (conectores discursivos, ítems léxicos y estructuras sintácticas, entre otros) ${ }^{1}$. A su vez, cada movida se compone de pasos, unidades funcionales y retóricas menores. El estudio de unidades funcionales prototípicas permitió caracterizar diversos géneros discursivos, entre ellos, el editorial periodístico, en el que fueron pioneros los aportes de Bolívar $(1994,1997)$. Esta autora postula un tipo de unidad, que denomina tríada y que consta de tres tipos de elementos estructurales, con funciones diferentes. En una línea similar, Ansary y Babaii (2005), y Bonyadi (2011) identifican segmentos textuales que aparecen con regularidad y en un orden determinado: el relato de los hechos que motivan el editorial; la introducción del tópico; la argumentación que apoya la tesis propia; y un segmento de cierre, donde se refuerza la tesis y se brindan recomendaciones. Así, los actos directivos parecen ser un rasgo presente en el segmento final de los editoriales periodísticos. 


\subsection{Actos de habla directivos}

Los actos de habla directivos, que representan la intención del hablante de lograr que el destinatario lleve a cabo una acción (Searle, 1979) y comprenden órdenes, pedidos, recomendaciones e instrucciones, fueron estudiados desde diferentes perspectivas: la Teoría de los Actos de Habla (Searle, 1975, 1979; la pragmalingüística (Mulder, 1993, 1998; Verstraete, 2001, 2005); la Lingüística Cognitiva (Pérez Hernández, 2001; Gras \& García, 2010, entre otros); la Lingüística SistémicoFuncional (Hyland, 2002, 2005; Briceño Velazco, 2012, 2013), y el Análisis del Discurso (López Samaniego \& Taranilla, 2012), entre otras. Hyland (2002, 2005), desde la Lingǘstica Sistémico Funcional y el estudio de lenguajes para propósitos específicos, señala que los directivos en artículos de investigación instruyen a los lectores a realizar tres tipos diferentes de actividades: textuales, físicas y cognitivas. Los directivos textuales forman parte de los componentes metadiscursivos, y poseen fines interactivos o de organización textual (Luukka, 1994; Hyland, 1998). Desde una perspectiva pragmática, según Mulder (1998: 242), los directivos metadiscursivos no serían directivos genuinos, sino enunciados que, "aunque tienen un valor directivo, actúan de sostén de otro acto de habla, y no pueden ser considerados como actos de habla directivos en sentido estricto". Mulder (1998) los denomina 'metadirectivos', y señala que estos pueden referirse al acto de habla involucrado, y también regular la interacción, por ejemplo, para llamar la atención de una persona y otorgarle el papel de oyente -'escucha', 'perdona', 'disculpa'- (Mulder, 1998).

Diversos autores intentaron establecer límites precisos entre los actos directivos (Pérez Hernández, 2001; Martínez-Flor, 2005; Verstraete, 2005; Gras \& García, 2010). Desde un abordaje semántico-pragmático, Verstraete (2005), para distinguir entre el permiso y la obligación, propone los conceptos de 'fuente modal' (la autoridad que otorga el permiso o impone la obligación) y el 'agente modal' (la persona que llevará a cabo la acción). Por su parte, desde la perspectiva de la Lingüística Cognitiva, Pérez Hernández (2001) propone un conjunto de parámetros cognitivos, como el tipo de agente, el grado de opción, el costo y el beneficio para los interlocutores, la atenuación de la fuerza ilocutiva, el poder y la distancia social, entre otros. Estos parámetros, de naturaleza gradual o escalar, se organizan en un modelo cognitivo idealizado (Lakoff, 1987)2. Según el grado de algunas variables, como el tipo de beneficiario y el grado de opción del destinatario, los directivos pueden acompañarse de otros actos de habla con fines persuasivos, por ejemplo, una justificación (Gallardo, 2005a, 2005b). Al respecto, en un análisis de un corpus de recomendaciones expertas, López Samaniego y Taranilla (2012) hallaron que la justificación es un componente constitutivo de la recomendación. En tal sentido, para el análisis de los actos de habla directivos resulta útil tener en tener en cuenta la estructura accional en que se insertan. Tales estructuras tienen una organización jerárquica, en cuya cúspide se sitúa la ilocución principal, que expresa el propósito comunicativo del hablante, y de ella surgen, como las ramas de 
un árbol, diversas funciones de apoyo (Brandt \& Rosengren, 1992; Gallardo, 2005a, 2009; Ciapuscio, 2010). Estas funciones de apoyo se orientan al cumplimiento de metas subordinadas: la comprensión del propósito comunicativo (mediante la explicación o la especificación); o la aceptación de la propuesta (mediante las razones que sustenten su propósito comunicativo).

Entre las funciones de apoyo, Brandt y Rosengren (1992) distinguen dos tipos: las subsidiarias, destinadas a asegurar de manera directa el éxito de la ilocución dominante; y las complementarias, orientadas a establecer una buena relación con el destinatario y también a destacar información relevante. Las funciones de apoyo constituyen un tipo especial de acciones lingüísticas que algunos autores han denominado 'acciones de composición textual' (Gülich \& Kotschi, 1987), y consisten en justificaciones, explicaciones, repeticiones y paráfrasis, entre otras. No obstante, una ilocución también puede cumplir una función de apoyo, por ejemplo, un consejo puede especificar otro consejo formulado previamente. Además de las funciones mencionadas, ciertos sintagmas que forman parte del contenido semántico de la ilocución, pero no constituyen por sí mismos una ilocución, también contribuyen al éxito comunicativo, a pesar de su menor relevancia comunicativa. Se trata de cláusulas subordinadas, sintagmas adverbiales o preposicionales.

En nuestra opinión, los componentes metadiscursivos del texto (Hyland, 1998, 2002, 2005) pueden equipararse a las funciones de apoyo en la propuesta de Brandt y Rosengren (1992), y a las acciones de composición textual del modelo de Gülich y Kotschi (1987). Asimismo, creemos que el análisis de la configuración jerárquica y secuencial que adoptan el acto de habla principal y las funciones de apoyo puede permitir determinar si una expresión de obligación realiza un acto de habla directivo con valor prescriptivo o una función de apoyo con un rol metadiscursivo.

\subsection{Realizaciones léxico-gramaticales de los actos directivos}

Los actos de habla directivos pueden realizarse mediante diversas configuraciones léxico-gramaticales: el modo imperativo; los verbos modales 'deber', 'poder', 'tener que' y 'haber que'; los adjetivos con valor deóntico ('es necesario que', 'lo importante es'); verbos performativos ('recomendar', 'suplicar'), entre otros (Mulder, 1998; Hyland, 2002, 2005). El agente de la acción propuesta puede estar explícito ('los médicos deben' / 'debemos'), o quedar implícito ('se debe'). En ciertos contextos, los verbos volitivos ('esperamos que', 'deseamos que') pueden tener un significado de obligación (Mulder, 1998). Ello es posible si se dan ciertas circunstancias pragmáticas, por ejemplo, la autoridad del hablante (Ridruejo, 1999). De acuerdo con Searle (1975), la expresión de un deseo constituye un acto de habla indirecto al afirmar que se cumple la condición de sinceridad (el hablante desea que el oyente realice una acción). El valor de obligación de los verbos y construcciones deónticas reside en que estos 
refieran a una acción futura. El verbo en pasado no impone una obligación sino que informa acerca de una obligación en el pasado (Palmer, 1995).

Entre las diferentes formas de expresar la obligación se puede establecer una gradación de mayor a menor fuerza o imposición que, en el marco de la Lingüística Sistémico Funcional, se organiza en tres niveles: alto medio y bajo. Las diversas formas en la escala fueron estudiadas en el español, en particular, en el discurso especializado (Gallardo, 2004a; Gutiérrez, 2008, 2010; Montolío, García, Gras, López \& Polanco, 2010). En el nivel alto, se ubica el modo imperativo y las perífrasis deónticas, como 'deber' o 'tener que' más infinitivo. En el grado medio, las perífrasis deónticas en modo condicional ('debería') y formas con el adjetivo de obligación ('es necesario que'). En el grado bajo, las estructuras como 'resulta útil', o enunciados que afirman los beneficios de la acción propuesta, que Montolío et al. (2010) designan 'estructuras inferenciales'. Al respecto, podemos mencionar las cláusulas condicionales, que presentan la acción que se recomienda como una condición para obtener un beneficio. Las formas comprendidas en el grado bajo de imposición pueden considerarse como directivos indirectos, enunciados cuya "forma lingüística se desvía de la función comunicativa que desempeñan” (Mulder, 1993: 182); el hablante realiza dos actos ilocutivos en forma simultánea, uno no-literal que se expresa mediante un enunciado literal. Según Mulder (1993), se puede admitir como acto indirecto toda forma que se refiera a una condición necesaria para que se cumpla la acción deseada, por ejemplo, en el consejo, una condición es que la acción propuesta sea beneficiosa para el destinatario. En consecuencia, un enunciado que haga referencia a ese beneficio puede interpretarse como un consejo. Cuando un acto directivo se realiza en forma indirecta, se supone, en general, que se trata de atenuar la imposición y el compromiso del hablante, pues el enunciado puede interpretarse de diversas maneras.

\section{Corpus y método}

En este estudio realizamos un análisis cualitativo y cuantitativo de un corpus compuesto por 45 textos que aparecen bajo el rótulo de Editoriales y fueron tomados del portal SciELO 3 . Corresponden a los años 2011 a 2013, y pertenecen a tres revistas especializadas editadas en la Argentina: Medicina, Archivos Argentinos de Pediatría, y Revista Argentina de Microbiología; en adelante nos referimos a ellas como Medicina, Pediatría y Microbiología, respectivamente. Los textos están firmados, principalmente, por los editores de las revistas y, en algunos casos, por profesionales que componen la comunidad de escritores o lectores de esas publicaciones. El corpus suma alrededor de 60 mil palabras.

En una primera etapa, distinguimos diversos tipos de editoriales según el propósito comunicativo y establecimos cuáles de ellos presentaban actos de habla directivos. 
Luego se analizaron los patrones retóricos de los textos, estableciendo movidas retóricas y pasos o subsegmentos textuales. En una segunda etapa, se analizaron las expresiones de obligación o necesidad, y se determinó el segmento textual en que aparece cada una de ellas. Luego se analizó la estructura ilocutiva de ese segmento para determinar si esa expresión realiza una ilocución principal o subsidiaria, y se indagó la función. En la secuencia ilocutiva, denominamos 'habilitaciones' a las razones que se formulan en forma previa al acto de habla principal, y justificaciones, a las que se expresan en forma pospuesta (Gallardo, 2005a). Según Beaugrande y Dressler (1981), la 'habilitación' es un tipo de relación causal en la que un hecho es una condición suficiente pero no necesaria respecto de otro hecho.

Para analizar las estructuras de obligación, consideramos la unidad proposicional (Krippendorff, 1997) mediante la cual se realiza un acto de habla, ilocución o función. Dicha unidad puede coincidir con la oración, aunque, en muchos casos, una oración puede contener varias unidades. Se consideran como estructura de obligación los verbos en imperativo; las perífrasis modales 'deber', 'tener que' y 'haber que'; los adjetivos con valor deóntico, como 'es necesario que'; las frases nominales como 'la necesidad de', y también las aserciones que pueden interpretarse como actos directivos indirectos, y las expresiones de deseo. El contexto en que analizamos la estructura de obligación es el segmento textual, o paso dentro de una movida retórica; este puede consistir en un párrafo, o en parte de un párrafo; su contenido proposicional se vincula a un subtópico del texto, y presenta una función, por ejemplo, introducir el tema del texto, o exponer un argumento de apoyo a la tesis principal. Cada segmento puede estar formado por una o varias cláusulas; y puede identificarse por medio de indicadores léxicos o por la presencia de un conector discursivo ('asimismo', 'sin embargo', 'finalmente'), entre otros.

\section{Análisis}

\subsection{Propósito comunicativo}

En primer lugar, los editoriales pueden diferenciarse según el propósito comunicativo. Así, identificamos cinco tipos, en coincidencia con Sabaj y González (2013). El tipo más frecuente es el que expresa opinión sobre un tema de la disciplina o la profesión; en general tal opinión es negativa, y la situación es planteada como un problema. El segundo de los tipos hallados es el que informa sobre un tema científico, con valoración positiva. En menor medida, aparecen editoriales de homenaje, de invitación o pedido a los lectores, o que comentan un artículo de la revista. La frecuencia de los distintos tipos varía según la revista. Por ejemplo, en Pediatría, el 93\% de los editoriales expresa una opinión negativa sobre un tema de la práctica profesional, mientras que sólo una tercera parte de los editoriales de Medicina presenta una perspectiva crítica (Tabla 1). Asimismo, los textos con postura crítica, en su totalidad, contienen actos de habla directivos que proponen cursos de acción 
orientados a modificar la situación evaluada como negativa. Los actos directivos también aparecen, como era esperable, en editoriales que formulan invitaciones o pedidos a su audiencia; muestran baja frecuencia en textos de carácter informativo; y están ausentes, al menos en nuestro corpus, en los editoriales de homenaje (Tabla 2).

Tabla 1. Número de editoriales según el propósito comunicativo.

\begin{tabular}{|l|c|c|c|}
\hline Propósito comunicativo & Microbiología & Medicina & Pediatría \\
\hline Opinión crítica & $8(53,3 \%)$ & $5(33,3 \%)$ & $14(93,3 \%)$ \\
\hline Información-opinión & $3(20.0 \%)$ & $8(53,2 \%)$ & -- \\
\hline Invitación / pedido & $1(6,6 \%)$ & -- & $1(6,6 \%)$ \\
\hline Homenaje & $3(20.0 \%)$ & $1(6,6 \%)$ & -- \\
\hline Comentario sobre artículo & -- & $1(6,6 \%)$ & -- \\
\hline Total & 15 & 15 & 15 \\
\hline
\end{tabular}

Tabla 2. Tipos de editoriales que incluyen actos directivos.

\begin{tabular}{|l|c|c|c|}
\hline Propósito comunicativo & Microbiología & Medicina & Pediatría \\
\hline Opinión crítica & 8 & 5 & 14 \\
\hline Información-opinión & -- & 1 & -- \\
\hline Invitación / pedido & 1 & -- & 1 \\
\hline Homenaje & -- & -- & -- \\
\hline Comentario sobre un artículo & -- & -- & -- \\
\hline Total & 9 & 6 & 15 \\
\hline
\end{tabular}

En algunos casos, los autores de los editoriales formulan de manera explícita el propósito comunicativo, ya sea en los primeros segmentos del texto, como se observa en (1); o al final, como se ejemplifica en (2); mientras que en otros resulta necesario inferirlo a partir del contenido (3).

(1) Comenzaremos esta mini-revisión sobre el Genoma Humano con algunas respuestas a preguntas básicas para adentrarnos luego con más soltura en algunos conceptos clave. [Medicina, 73/4]

(2) Resulta obvio que este Editorial es una defensa de Hans Selye ${ }^{4}$ como creador del concepto de stress.[...] [Medicina, 73/5]

(3) La investigación biomédica ha sido históricamente subsidiada en gran medida por instituciones gubernamentales y organizaciones filantrópicas sin fines de lucro. [...] Sin embargo, en los últimos 20 años, los capitales privados han incrementado su participación brindando soporte económico a numerosos proyectos de investigación. [...] una consecuencia negativa de esta interacción podría ser el hecho de que el origen de los fondos con los que se llevan a cabo los proyectos de investigación o los ensayos clínicos influyera en la dirección que toman las investigaciones y en la calidad de las publicaciones realizadas a partir de ellas. Esta influencia podría perjudicar la integridad científica e interferir en el impacto de la investigación sobre la salud pública. [Microbiología 45/3] 
Una forma de explicitar el propósito comunicativo es el empleo de un verbo de proceso verbal o cognitivo, o una frase nominal que incluya un nombre deverbal que permita etiquetar el texto como una opinión, una reflexión, un homenaje o un informe. Como se puede observar en (1), los autores definen el texto como una revisión, dando cuenta de un propósito informativo; en (2), mediante el nombre deverbal 'defensa' se explicita el objetivo de homenajear a alguien. En este caso, la autora formula la aclaración al final del artículo; no obstante, a través de la expresión de modalidad epistémica asertiva ('resulta obvio') sugiere que tal propósito se infería a partir de la información consignada. En (3), cuyo tema es el aumento del capital privado en la financiación de las investigaciones, los ítems léxicos de valoración negativa ('consecuencia negativa', 'perjudicar', 'interferir'), y los indicadores de modalidad epistémica que atenúan la fuerza de las afirmaciones (el verbo 'poder' en condicional) permiten inferir una intención crítica.

\subsection{Estructura retórica de los editoriales}

En los textos se pueden identificar tres segmentos textuales: I) la introducción, II) el desarrollo y III) el cierre o conclusión, de manera similar a lo hallado en los editoriales periodísticos (Ansary \& Babaii, 2005; Bonyadi, 2011), y en editoriales de revistas biomédicas (Vázquez y del Árbol, 2005). La introducción puede constar de dos o tres pasos o subsegmentos: 1.1) la situación, o relato de los hechos principales que motivan el artículo; I.2) la introducción del tema textual y el propósito comunicativo, y I.3) la afirmación de la tesis principal. En la movida II -el desarrollo-, los autores aportan los argumentos para sostener su tesis. Finalmente, en el cierre o conclusión se refuerza la idea principal del texto y se formulan las recomendaciones o sugerencias como solución al problema planteado; aquellos editoriales cuyo propósito es invitar a sus lectores a publicar en la revista formulan ese acto directivo en la movida final del texto. En esta movida final es donde, con mayor frecuencia, se formulan actos directivos, aunque estos se encuentran también distribuidos a lo largo del texto. Con el fin de ejemplificar, a continuación presentamos la estructura retórica de un editorial del corpus. 
Tabla 3. Estructura retórica de un editorial. [Mejor medicina o más medicina, ¿hacia dónde vamos? Pediatría,111/5]

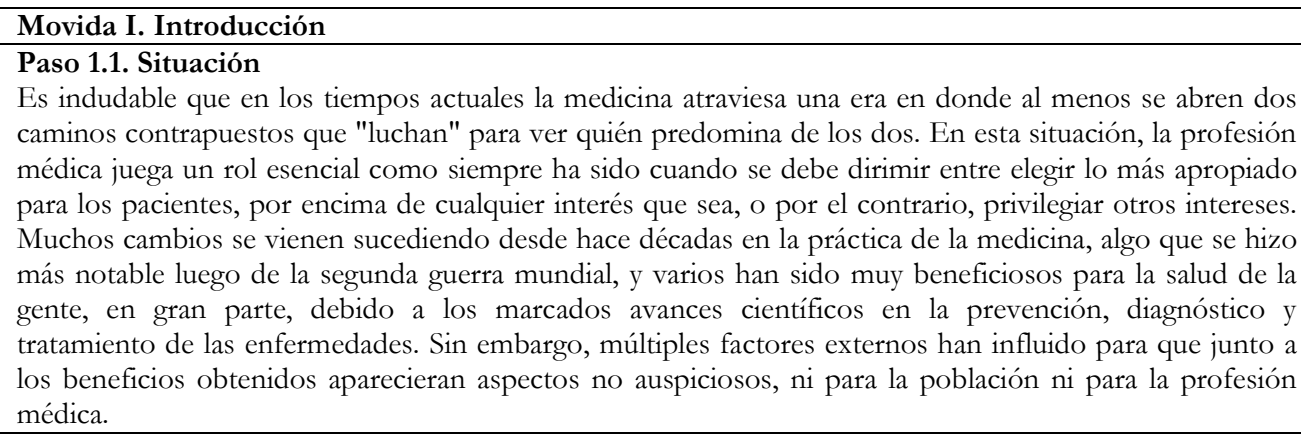

\section{Paso I.2. Introducción del tema}

Deseo hacer algunas reflexiones acerca de uno de estos últimos aspectos que tiene que ver con los caminos que mencioné al comienzo. A mi juicio, hay dos caminos contrarios, uno es el que nos lleva a una mejor medicina y el otro el que nos conduce a tener más medicina.

\section{Paso I.3. Afirmación de la tesis principal}

¿Qué entendemos por mejor medicina? Creo que esto no debería requerir de mayores explicaciones, aunque no estoy seguro de que siempre sea así. Una buena medicina es aquella que la gente realmente necesita y que está basada principalmente en los siguientes principios, [...] Es más fácil definirla que cumplir con esos preceptos, por lo cual debemos bregar fuertemente para que no decaigan los ímpetus ancestrales de la medicina, "el cuidado de la salud y el alivio de los que sufren", ya que de lo contrario estaríamos alejándonos progresivamente de una mejor medicina. ¿De qué hablamos cuando decimos más medicina? Hay varios componentes que participan en esta definición de los cuales solo señalaré los que considero más relevantes hoy en día. Uno de los aspectos importantes es la creciente medicalización en la vida de las personas, algo que ya mencioné en un editorial reciente y por lo tanto no voy a referirme a los conceptos generales, y solo lo haré a sus formas más perniciosas.

\section{Movida II. Desarrollo}

\section{Paso II.1.}

El principal aspecto de esta medicalización es el diagnóstico excesivo y no sustentado [...]

\section{Paso II.2}

Otro esencial aspecto a señalar es la progresiva ampliación de la definición de qué es una enfermedad, lo cual puede $[\ldots]$

\section{Paso II.3}

Algunos programas de cribado o pesquisa están detectando cánceres en etapa inicial que no causan síntomas ni provocarán la muerte $[\ldots]$

\section{Paso II. 4}

Asimismo, la ampliación de las definiciones de enfermedad, hace que aparezcan "nuevas" enfermedades $[\ldots]$

\section{Paso II.12}

No deseo explayarme en este tema que es muy extenso y que hace a los principios éticos de nuestra profesión, hoy tan vapuleados, solo señalaré una frase significativa de Julian Tudor Hart, prestigioso médico inglés que practicó la medicina general muchos años y se destacó como notable epidemiólogo. En 1971 publicó en Lancet [...]

\section{Movida III. Conclusión o cierre}

Es necesario comprender que nosotros, los médicos, somos los que debemos bregar en cada uno de los actos que realizamos para que esta realidad cambie ya que desvirtúa claramente los fines de la medicina. En una era donde deslumbran los aparentes "milagros" en la atención médica y el encandilamiento por la apabullante tecnología, como así también donde los preceptos éticos de nuestra profesión tambalean, el trabajo silencioso y humilde de la mayoría de los médicos puede cambiar el rumbo de esta creciente y perniciosa situación que hoy agobia a los que deseamos una medicina mejor. 
El texto ejemplificado en la Tabla 3 (en forma abreviada) presenta una valoración crítica de la práctica médica, cuestionando el exceso en el diagnóstico de enfermedades y la administración de medicamentos. La movida I (introducción), consta de tres pasos: el primero presenta la situación o los hechos que motivan el artículo; el segundo introduce el tema y el propósito comunicativo: reflexionar (opinar) sobre lo que el autor entiende como buena y mala medicina. En el paso 3, se definen tales conceptos, y se afirma la tesis principal: la creciente medicalización de la vida tiene efectos perniciosos. En la movida II -desarrollo-, a través de doce subunidades o pasos, se introducen numerosos argumentos para sostener la tesis planteada: el diagnóstico excesivo, la ampliación de lo que se considera como enfermedad, y el exceso de medicación en determinados casos, entre otros. Cada uno de los pasos se identifica por la introducción de un diferente tópico en posición temática $\mathrm{y}$, en algunos, la presencia de un conector de adición, como 'asimismo', o frases nominales o preposicionales que contienen un determinante ('otro aspecto'), o un adjetivo ordinal ('en primer lugar'). En la movida III (cierre), el autor exhorta a sus colegas a luchar por una mejor medicina. En algunos textos, esta movida puede iniciarse mediante un marcador metadiscursivo, como 'finalmente', 'en síntesis'; pero en muchos otros se inicia con una estructura de obligación, como en el texto ejemplificado. En líneas generales, la estructura retórica de estos editoriales tiene los componentes de un razonamiento: tesis, argumentos y conclusión; y los actos prescriptivos del cierre funcionan como conclusión.

\subsection{Expresiones de obligación}

Las expresiones de obligación (verbos y perífrasis deónticas, verbos en imperativo, adjetivos con valor deóntico, entre otras) halladas en los textos pueden ordenarse en dos grupos según el tipo de acción que se propone y el agente. Por un lado, identificamos un grupo de expresiones de obligación que presentan un carácter claramente prescriptivo y aparecen sobre todo en la movida final de los editoriales; pueden contener verbos de acción ('implementar', 'mejorar', 'continuar', 'cambiar'); verbos cognitivos ('reflexionar', 'recordar', 'reconocer'); o verbos de voluntad ('bregar', 'aceptar', 'adaptarse'). El agente es el destinatario, aunque puede tratarse de un colectivo que incluya también al emisor (mediante la primera persona del plural). Asimismo, el agente puede ser un tercero, un destinatario indirecto: las autoridades o los encargados de diseñar políticas públicas. El segundo grupo de expresiones de obligación incluye, principalmente, verbos de proceso verbal, por ejemplo, 'destacar', 'analizar' y 'mencionar', entre otros. En algunos casos, la construcción se forma con un verbo volitivo, en primera persona del singular: 'deseo señalar', 'deseo aclarar'. En todos estos casos, los verbos en infinitivo refieren actividades textuales que realiza el emisor en el texto. Mediante el imperativo, en primera persona del plural ('detengámonos en discutir') se incluye al destinatario, aunque este no siempre pueda realizar la acción verbal. Con verbos de percepción visual ('veamos') o verbos 
cognitivos ('recordemos que'), las actividades propuestas pueden ser realizadas por el destinatario.

Al respecto, cabe mencionar el trabajo de Tang y John (1999) sobre los roles discursivos que desempeña el autor en artículos de investigación, donde distinguen entre el rol de guía, que dirige la atención del lector, y el de arquitecto, que organiza y estructura el texto. En el primero, pueden emplearse verbos de percepción visual en imperativo. En cambio, en el de arquitecto, los verbos de habla, como 'especificar', 'aclarar' y 'mencionar', refieren a actividades discursivas que realiza el productor textual (Gallardo, 2004b). En la Tabla 4 se muestra la frecuencia de las diferentes formas léxico-gramaticales empleadas para expresar directivos metadiscursivos y prescriptivos, ordenadas desde las más impositivas (modo imperativo y perífrasis deónticas), hasta las menos impositivas (perífrasis deónticas en modo condicional, expresiones de deseo y cláusulas condicionales). En la tabla no se incluyen otros directivos hallados en el corpus, como las invitaciones y pedidos, que presentaron muy baja frecuencia.

Tabla 4. Directivos prescriptivos y metadiscursivos: Formas léxico-gramaticales.

\begin{tabular}{|l|l|c|c|c|}
\hline \multicolumn{1}{|c|}{ Directivos } & \multicolumn{1}{|c|}{ Formas léxico-gramaticales } & Medicina & Microbiol. & Pediatría \\
\hline Metadiscursivos & Modo imperativo & 5 & 4 & - \\
\hline & Perífrasis deóntica & 2 & 10 & 3 \\
\hline & Adj. deóntico: 'necesario' 'importante' & 4 & 6 & 2 \\
\hline & Expresión de deseo & - & 1 & 5 \\
\hline Total metadiscur. & & $\mathbf{1 1}$ & $\mathbf{2 1}$ & $\mathbf{1 0}$ \\
\hline Prescriptivos & Modo imperativo & 7 & 2 & 3 \\
\hline & Perífrasis deóntica & 14 & 13 & 24 \\
\hline & Adj. deóntico: 'necesario' 'importante' & 5 & 7 & 11 \\
\hline & V. de obligación 'requiere', 'necesita' & 3 & 5 & 3 \\
\hline & Perífrasis epistémica con 'poder' & 3 & - & 4 \\
\hline & V.performat.: 'aconsejar' 'recomend.' & - & 1 & 1 \\
\hline & Expresión de deseo & 1 & 4 & - \\
\hline & Formas indirectas & 6 & 3 & 13 \\
\hline Total prescriptiv. & & $\mathbf{3 9}$ & $\mathbf{3 4}$ & $\mathbf{5 9}$ \\
\hline
\end{tabular}

Como era esperable, los directivos que presentan mayor frecuencia son prescriptivos: recomendaciones de acciones concretas o de procesos cognitivos para ser realizados por los destinatarios con el fin de modificar un estado de cosas que es valorado como negativo (ver sección 3.3.1). En cuanto a los directivos metadiscursivos, que destacan información relevante en el texto, mostraremos en la sección 3.3.2 que estos, desde el punto de vista de la jerarquía ilocutiva, desempeñan una función de apoyo de una ilocución asertiva dominante. Cabe señalar que los directivos prescriptivos, además de presentar mayor frecuencia, muestran una amplia variedad de formas léxico-gramaticales e incluyen formas implícitas, como las cláusulas condicionales que detallan los beneficios de realizar la acción propuesta. Los directivos prescriptivos presentan mayor frecuencia en la revista Pediatría, cuyos 
editoriales, en su mayoría, dan una opinión crítica acerca de un estado de cosas. En la sección 3.3.3 nos centramos en directivos que se interpretan como prescriptivos según el tipo de acción propuesta y el agente, pero cuyo valor performativo se acerca más a una evaluación por tratarse de enunciados que expresan funciones de apoyo de ilocuciones asertivas.

\subsubsection{Actos directivos con valor prescriptivo}

En la movida de cierre o conclusión del texto, la mayor parte de las expresiones de obligación realizan recomendaciones o sugerencias. Dos de los textos del corpus formulan una invitación a los miembros de la comunidad disciplinar que lee la revista (ejemplo 4).

(4) El Comité Editor de la Revista Argentina de Microbiología renueva la invitación a la comunidad científica argentina e internacional a considerarla una opción preferente para la divulgación de su producción científica. Colaboremos en el crecimiento de la RAM y contribuyamos a mejorarla; la RAM también es nuestro Patrimonio Nacional y nos representa ante el mundo. [Microbiología, 45/2]

En una invitación, el beneficio es para el destinatario, y también puede haber beneficio para el emisor, lo cual es claro en (4). En efecto, luego de la invitación, el autor formula un pedido, en imperativo y primera persona del plural, que también funciona como justificación de la invitación: al publicar en la revista, los autores estarían colaborando al crecimiento de esta. La aserción acerca del carácter de patrimonio nacional de la revista también contribuye a justificar la acción propuesta. De este modo, un acto directivo es apoyado por otros directivos, que a su vez se apoyan con un acto asertivo. La justificación de la invitación explicitando el beneficio para el emisor lleva a interpretar el acto de habla como una invitación no prototípica, o como un pedido (Pérez Hernández, 2001).

Secuencia ilocutiva de (4): [lloc. Principal directiva Invitación ('el Comité Editor renueva la invitación')] $\leftarrow$ F. de apoyo directiva Pedido/Justificación ('colaboremos'... 'y contribuyamos'...)] F. de apoyo Justificación en un segundo nivel ('la RAM es nuestro patrimonio')]

Los actos directivos no impositivos, como consejos y sugerencias, proponen acciones para beneficio del destinatario. En el corpus, el beneficiario es un colectivo que incluye a emisor y destinatario, a los pacientes y, también, a la sociedad en general. En estos casos, la obligación se expresa mediante construcciones impersonales (sin explicitación del agente), o en primera persona del plural. El agente, explícito o inferido del contexto, puede ser de dos tipos: el destinatario directo del texto (los miembros de la comunidad disciplinar que lee la revista), como se muestra en (5); o un destinatario indirecto (autoridades y políticos), como se observa en (6): 
(5) Finalmente, deseo señalar una nueva estrategia que significa un notable cambio cultural y es el de asociarse con los pacientes para mejorar su seguridad. Recientemente aplicada en EE.UU. (Partnership for Patients) requiere, como ya señalé $[. .$.$] , reunir a los líderes de los hospitales y a todos$ los profesionales y empleados junto con el Estado y los gobiernos provinciales para difundir y aplicar esta estrategia. Eso implica estimular a los pacientes en su propio cuidado y brindarles información adecuada para la prevención de errores a fin de mejorar la seguridad en su atención. Esto tendrá beneficios importantes tanto para ellos mismos como para médicos y enfermeras/os que cambiarán su forma habitual de actuar por sí solos y los llevará a comunicarse apropiadamente con los pacientes. Si consideramos "socios" a los pacientes, la comunicación mejorará sensiblemente. [Pediatría, $111 / 2]$

(6) Teniendo en cuenta las evidencias que demuestran la ubicuidad del CI [conflicto de interés] en la ciencia y su intrincada relación con las publicaciones científicas, es importante que la elaboración de las políticas destinadas a controlar los CI en los tiempos que transcurren cuente con la participación de la comunidad científica, las instituciones públicas y privadas y las editoriales. Estas políticas deberían incluir la aplicación de teorías sociales y psicológicas que en conjunto den origen a un mecanismo capaz de supervisar y controlar el CI, maximizando los beneficios de la interacción público-privada y reduciendo sus consecuencias negativas. [Microbiología, 45, 3]

El fragmento (5) pertenece a la movida de cierre de un editorial acerca de las consecuencias de los errores médicos. La cláusula inicial incluye una expresión de deseo, en primera persona del singular, con función metadiscursiva: destacar la información que sigue. Se trata de una aserción que puede interpretarse como un directivo indirecto. La propuesta ('asociarse con los pacientes para su beneficio') se expresa con más detalle en las cláusulas que siguen, mediante ilocuciones directivas especificadoras. También funcionan como apoyos las aserciones que dan cuenta de los beneficios que proporcionarán las acciones propuestas, donde queda claro quiénes son los beneficiarios: los pacientes y también los médicos. En la última frase, la cláusula condicional, en primera persona del plural, presenta un valor directivo indirecto. En términos de Pérez Hernández (2001) esta propuesta de acciones a un agente que incluye al emisor (por la primera persona del plural en la última cláusula) puede considerarse como una sugerencia [[Iloc. Principal directiva Sugerencia ('deseo señalar una nueva estrategia'...) $] \leftarrow[$ F. de apoyo directivas Especificadoras ('recientemente aplicada... requiere'...) - ('eso implica estimular a los pacientes y brindarles información'...) $\leftarrow[$ F. de apoyo Justificación ('esto tendrá beneficios importantes'...] $\leftarrow[$ F. de apoyo directiva Sugerencia ('si consideramos socios'...)].

En (5), el autor recomienda a los destinatarios un curso de acción y, teniendo en cuenta el grado de opción de estos, los persuade mediante funciones de apoyo que a 
su vez contienen expresiones de obligación relacionadas con la dimensión ética de la profesión médica. En (6), la propuesta de acciones se orienta a controlar los conflictos de interés en las publicaciones científicas. El agente es un tercero: las autoridades o los responsables de políticas públicas; el beneficiario es la comunidad científica y la sociedad en general. El acto de habla principal -una recomendación- se encuentra habilitado por la cláusula de gerundio que da inicio al segmento, pues el hecho de ser consciente de una situación negativa habilita o autoriza al emisor a formular una recomendación. El segundo directivo ('debería') especifica al primero, detallando cómo se podrían controlar los conflictos de interés. El contenido proposicional de las cláusulas de gerundio describe el objetivo de la recomendación.

Se muestra la secuencia ilocutiva de (6): [F. de apoyo Habilitadora ('Teniendo en cuenta evidencias'...) $\rightarrow$ [lloc. princ. directiva Recomendación ('es importante que'...)] $\leftarrow$ [F. de apoyo directiva Especificadora ('Estas políticas deberían’...)]

En los textos también se formulan advertencias, que muestran al interlocutor un hecho o situación que puede ser riesgosa, con el fin de que pueda evitarlo, para su beneficio o para el de la sociedad:

(7) Como podemos apreciar, esta revolución en el estudio de las células madre (más de 31000 citas en Google Académico y más de 81 millones en Google), requiere de una información certera para los médicos no especializados y para el público en general. No por pensar en Prometeo abramos nuevamente $\underline{\text { la caja de Pandora, }}$ aun sabiendo que en ella queda la esperanza. [Medicina, $72 / 5]$

El ejemplo (7) muestra el segmento de cierre de un texto que trata sobre las investigaciones en células madre, y donde se destaca que los médicos y el público en general necesitan disponer de información sobre el tema. No se especifica el agente de la acción, que no es el destinatario directo (la audiencia de la revista), sino uno indirecto: los investigadores que producen esa información. Aquí caben dos posibles interpretaciones: puede tratarse de una forma indirecta de recomendar a los médicos que se informen, pero también podría leerse como una simple aserción acerca de que estos carecen de información sobre el tema. La cláusula final constituye una advertencia; mediante el imperativo negado 'no abramos', se expresa una prohibición, dirigida a los médicos lectores de la publicación. Esta prohibición, expresada en forma metafórica ('la caja de Pandora'), puede tomarse como una advertencia.

Secuencia ilocutiva de (7): [lloc. Principal directiva Recomendación ('esta revolución en células madres requiere de información'...) $] \leftarrow[$ F. de apoyo directiva Advertencia ('no abramos la caja de Pandora'...)] $\leftarrow$ [F. de apoyo concesiva ('aun sabiendo que queda esperanza')]

Como pudimos observar en los ejemplos presentados, los directivos en el segmento final de los editoriales constituyen la ilocución principal en la jerarquía de 
acciones verbales del segmento, y se encuentran apoyados por otras funciones, como habilitaciones, justificaciones y especificaciones.

\subsubsection{Expresiones de obligación con función metadiscursiva}

En el corpus se observan expresiones de obligación que cumplen el rol de focalizar información relevante: son expresiones metadiscursivas (Luukka, 1994; Hyland, 1998) o acciones verbales de composición textual (Gülich \& Kotchi, 1987). En general, incluyen un verbo de habla como 'destacar', 'subrayar' o 'aclarar', cuyo agente es el emisor.

(8) En este contexto, es necesario destacar que, aunque los dos tipos de CI secundario antes mencionados (origen financiero y origen académico) deben ser considerados seriamente, el segundo es mejor controlado durante el proceso científico $y$ en el marco de las políticas institucionales. [Microbiología, 45/3]

El ejemplo (8) pertenece a un editorial en el que se argumenta a favor de la necesidad de controlar los conflictos de interés en la investigación científica. La primera expresión de obligación (compuesta por el adjetivo 'necesario' más un verbo de habla) introduce, y evalúa como relevante, una aserción (locución principal del segmento) acerca del conflicto de origen académico. De este modo, la expresión constituye un marcador de evaluación del contenido proposicional, y podría ser eliminada sin afectar el sentido de la oración. El agente del verbo 'destacar' es el emisor y, así, habría coincidencia entre fuente y agente del directivo. No obstante, si el enunciado se interpreta como un acto de habla indirecto, el agente sería el destinatario, que estaría siendo exhortado a prestar especial atención a la frase. En este caso, si bien la forma literal expresa un acto que es realizado por el emisor, el acto indirecto expresaría una exhortación o un pedido que, de este modo, se encuentra mitigado. Teniendo en cuenta que los actos indirectos suelen referir a las condiciones para que el acto de habla pueda realizarse, en este caso, la acción verbal de destacar información por parte del emisor podría ser una condición para que el destinatario preste mayor atención a esa información. En el mismo fragmento (8), la perífrasis deóntica 'deben ser considerados' forma parte del contenido de una cláusula concesiva que sirve de apoyo a la ilocución principal. Por tal razón, este enunciado aparece como presupuesto, como si hubiera sido formulado previamente por un locutor a quien el emisor concede el acuerdo y, de este modo, la función directiva de la perífrasis de obligación aparece en un segundo plano.

Secuencia ilocutiva de (8): [Función complementaria metadiscursiva ('es necesario destacar')] [Función de apoyo subsidiaria Concesiva ('aunque los dos tipos de CI deben ser considerados')] $\rightarrow$ [locución principal asertiva ('el segundo es mejor controlado')]. 


\subsubsection{Actos prescriptivos como apoyo}

En los segmentos informativos del texto, en los que se exponen los argumentos para sostener la posición que se defiende, aparecen expresiones de obligación en cláusulas que funcionan como apoyo de un acto de habla asertivo. Estas expresiones no parecen remitir a una acción futura sino que describen una obligación o un deseo con el carácter de habituales, y dan cuenta de un estado de cosas, como se muestra a continuación.

(9) En el convencimiento de que la sociedad en general debe conocer estas realidades y jugar un papel importante en las decisiones en salud, estos datos fueron difundidos en conferencia de prensa con amplia repercusión en todo el país. Son pasos en el camino que estamos decididos a recorrer para hacer efectiva y digna la privilegiada tarea de cuidar a nuestros chicos. [Pediatría, $110 / 4]$

En (9), la cláusula que contiene el verbo modal 'deber' realiza una función de apoyo que habilita o da las razones para la aserción, que es la ilocución principal del segmento. Al encontrarse en una cláusula subordinada, la obligación no es afirmada sino presupuesta, presentada como algo ya conocido en el contexto. Si bien no negamos que la expresión de obligación pueda interpretarse como una propuesta para el destinatario, la intención principal del emisor es informar que determinados datos fueron difundidos a la prensa, y la función directiva realizada en la expresión de obligación aparece en segundo plano.

Secuencia ilocutiva de (9): [F. de apoyo Habilitadora ('la sociedad debe conocer'...)] $\rightarrow$ [locución principal ('estos datos fueron difundidos'...)] $\leftarrow$ [(F. de apoyo Justificación ('son pasos en el camino’...)]

En el ejemplo siguiente, la expresión de obligación, con interpretación asertiva, se encuentra pospuesta a la ilocución principal, y así forma parte de una justificación.

(10) El Factor de Impacto (FI), aunque criticado por su uso inadecuado, es el «sistema métrico» de evaluación más reconocido por la comunidad científica nacional e internacional para evaluar y categorizar a las revistas científicas. Desafortunadamente se ha desviado mucho este objetivo legítimo, y muchas comisiones evaluadoras lo utilizan para evaluar la producción científica de un investigador y al investigador mismo, a través del FI de las revistas en las cuales publica. Esto es decididamente un despropósito, dado que el FI expresa la calidad global de una revista pero no garantiza la homogeneidad en cuanto a excelencia de todos los trabajos que se publican en ella, y tampoco la de todos los investigadores. Para evaluar la calidad científica de un trabajo se debe, simplemente, realizar la lectura crítica del mismo. [Microbiología, 45/2]

En el fragmento ejemplificado en (10), el acto de habla principal es cuestionar el factor de impacto de las publicaciones como criterio para evaluar la producción 
científica de un investigador. La cláusula final, que incluye un verbo deóntico, funciona como apoyo del acto de habla principal, pues señala cuál es, en opinión del autor, la forma legítima de evaluar un trabajo científico. El verbo deóntico puede tener una interpretación directiva (instruir al destinatario sobre cómo evaluar la calidad de un trabajo), o describir un procedimiento habitual en el arbitraje de artículos de investigación. El adverbio 'simplemente' es un indicador de actitud, que equivale a decir que la lectura crítica del trabajo es suficiente. La frase podría tener un doble valor: funcionar como apoyo y, al mismo tiempo, como recomendación para quienes valoran solo el factor de impacto.

Secuencia ilocutiva de (10): [locución principal asertiva ('el FI como criterio para evaluar investigadores es un despropósito')] [F. de apoyo subsidiaria Justificación ('para evaluar se debe realizar lectura crítica')]

\section{CONCLUSIONES}

Con el fin de contribuir a la caracterización del género editorial de revistas científicas especializadas, en este trabajo hemos intentado determinar las funciones de las expresiones de obligación que son empleadas con alta frecuencia en este género. Una primera conclusión es que los textos presentan dos tipos de actos de habla directivos: los prescriptivos, que proponen acciones para ser realizadas por los destinatarios, y los metadiscursivos, que tienen la función de destacar información relevante en el texto.

Los directivos prescriptivos que expresan recomendaciones son los que alcanzan mayor frecuencia, y aparecen principalmente en editoriales que manifiestan una opinión crítica sobre un estado de cosas vinculado a la disciplina o a la práctica profesional. Este tipo de editoriales mostró alta frecuencia en el corpus, en particular en una de las revistas analizadas, aunque también hallamos editoriales que respondían a otros propósitos comunicativos, en coincidencia con resultados de Sabaj y González (2013). El análisis sugiere una relación entre el propósito comunicativo del texto, la estructura retórica y el empleo de directivos con valor prescriptivo. En efecto, aquellos textos de carácter crítico proponen, en el cierre, un conjunto de acciones como solución a la situación planteada; esta presencia de recomendaciones en el segmento final del texto coincide con lo observado por diversos autores en los editoriales periodísticos (Bolívar, 1994, 1997; Ansary \& Babaii, 2005; Bonyadi, 2011). La formulación de recomendaciones en la movida final sugiere que éstas funcionan como la conclusión de un razonamiento desarrollado a lo largo del texto. Algo similar sucede en artículos periodísticos sobre salud (Gallardo, 2005b). De este modo, la descripción de una situación evaluada en forma negativa podría conducir a proponer una manera de modificar ese estado de cosas y solucionar el problema planteado. 
Los directivos metadiscursivos se corresponden con los que Mulder (1998) designa como metadirectivos. Estos, aunque tienen valor directivo, actúan de sostén de otro acto de habla y, según este autor, no pueden considerarse como directivos en sentido estricto. Asimismo, pueden equipararse a las actividades textuales señaladas por Hyland (2002, 2005), quien incluye dentro de ese grupo aquellas acciones como 'ver' o 'consultar', que tienen como agente al destinatario. En nuestro corpus, encontramos verbos cognitivos ('reflexionar', 'considerar') o de percepción visual, en imperativo y primera persona del plural, que incluyen al destinatario como agente. Pero también aparecen verbos como 'aclarar' y 'mencionar', entre otros, cuya realización corresponde al productor textual. No obstante, tales directivos pueden interpretarse como actos de habla indirectos. Este tipo de directivos afectan solo a ciertos elementos del enunciado (Mulder, 1993), en este caso al verbo que refiere a la acción propuesta, pero no modifican la fuerza ilocutiva, que es directiva. Así, el sentido literal del directivo es proponer una acción que realiza el emisor, pero el sentido indirecto podría ser la exhortación al destinatario para que preste especial atención a la información que se consigna. El empleo de una forma indirecta, en este caso, se interpreta como un procedimiento de atenuación.

No obstante, la gran mayoría de los directivos metadiscursivos que aparecen en el corpus se caracterizan por la baja atenuación (por ejemplo, el empleo del imperativo), mientras que los prescriptivos se realizan mediante formas más variadas, con mayor atenuación, y también mediante formas implícitas, como las cláusulas condicionales que indican el beneficio de realizar la acción propuesta. Es razonable pensar que el directivo metadiscursivo que propone actividades textuales, realizadas por el emisor durante la composición del texto, o por los destinatarios durante la lectura, no implican una amenaza a la imagen del destinatario (véase Brown \& Levinson, 1987). En cambio, los prescriptivos, que proponen acciones a ser efectuadas en el mundo real, pueden implicar una intromisión en la libertad de acción de los destinatarios y, por ello, requerir atenuación (Pérez Hernández, 2001; Gallardo, 2005a).

Por consiguiente, los directivos metadiscursivos se diferencian de los prescriptivos, por un lado, por el tipo de actividad propuesta (verbales y cognitivas); por el tipo de agente, que en muchos casos puede ser el emisor, y por un menor grado de atenuación. Mientras que las recomendaciones pueden realizarse en forma indirecta, por ejemplo, mediante cláusulas condicionales que afirman el beneficio de realizar la acción propuesta; los directivos metadiscursivos presentan un carácter indirecto que sólo afecta a ciertos elementos léxico-semánticos (el tipo de verbo y, por ende, el tipo de agente), sin afectar la fuerza ilocutiva. Otra forma de explicar la diferencia entre directivos prescriptivos y metadiscursivos es considerar la estructura ilocutiva del segmento en que se insertan. En el análisis, pudimos observar que una expresión de obligación realiza un acto prescriptivo si la ilocución directiva es dominante en un segmento textual. En cambio, si la expresión de obligación funciona como apoyo de 
una dominante asertiva, su valor prescriptivo aparece en segundo plano. Lo mismo se observa en construcciones de obligación de valor prescriptivo que forman parte del contenido proposicional de funciones de apoyo de ilocuciones asertivas y cuyo valor prescriptivo también aparece en segundo plano.

La presencia significativa de expresiones de obligación en los editoriales de revistas especializadas puede deberse, como señaló Salager-Meyer (2002), a la intención de los autores de indicar su compromiso e intención persuasiva. En las revistas analizadas, los autores de editoriales son personas reconocidas en el área, con posición relevante en las diversas sociedades profesionales, características que les dan autoridad para formular actos prescriptivos a su audiencia. Por otra parte, los directivos con función metadiscursiva contribuyen a la función persuasiva de involucrar a los lectores en la línea de razonamiento del texto, en especial si son expresados en primera persona del plural. El hecho de que los actos prescriptivos se formulen en el segmento final, los hace aparecer como la conclusión del razonamiento desarrollado.

En resumen, los actos directivos cumplen un rol relevante en los editoriales de revistas científicas, y el análisis de la estructura accional de los segmentos textuales en que aparecen formulados puede contribuir a determinar su función. De todos modos, estas observaciones tienen un carácter preliminar, teniendo en cuenta lo acotado del corpus, y deberían ser corroboradas en corpus más amplios y en otros géneros discursivos. No obstante, creemos que constituyen un camino para seguir indagando el empleo de las expresiones de obligación y los rasgos que influyen en su interpretación prescriptiva. 


\section{REFERENCIAS BIBLIOGRÁFICAS}

Ansary, H. \& Babaii, E. (2005). The generic integrity of newspaper editorials: A systemic functional perspective. Regional Language Centre Joumal, 36(3), 271 295.

Beaugrande, R. de \& Dressler, W. (1981). Introduction to text linguistics. Londres/Nueva York: Longman.

Bolivar, A. (1994). The structure of newspaper editorials. En M. Coulthard (Comp.), Advances in written text analysis (pp. 276-294). Londres: Routledge.

Bolívar, A. (1997). La negociación de la evaluación en editoriales de periódicos. Boletín de Filología, Tomo XXXVI, 7-24.

Bonyadi, A. (2011). Linguistic manifestations of modality in newspaper editorials. International Journal of Linguistics, 3(1), 1-13.

Brandt, M. \& Rosengren, I. (1992). Zur Illokutionstruktur von Texten. Zeitschrift für Literaturwissenschaft und Linguistik, 86, 9-51.

Briceño Velazco, Y. (2012). Las marcas lingüísticas de obligación en artículos de investigación en tres disciplinas. Filología y Lingüística, 38(2), 77-95.

Briceño Velazco, Y. (2013). 'Debe aclararse que’: Una exploración al modal debe en artículos de investigación en humanidades y en ciencias básicas y aplicadas. Signo y Seña, 24, 123-144.

Briceño Velazco, Y. (2014). 'Aparentemente usted': Postura y compromiso en editoriales de dos revistas venezolanas de gerencia. Signo y Pensamiento, 33(65), 84-102.

Brown, P. \& Levinson, S. (1987). Politeness, Some universals in language usage. Cambridge: Cambridge University Press.

Ciapuscio, G. (2010). Estructura ilocucionaria y cortesía: La construcción de conocimiento y opinión en las cartas de lectores de ciencia. Revista Signos. Estudios de Lingüistica, 43(s1), 91-117.

Gallardo, S. (2004a). Realizaciones léxico-gramaticales de la recomendación en artículos de medicina en la prensa escrita. Revista de Lingüística Teórica y Aplicada, 42(1), 111-135.

Gallardo, S. (2004b). La presencia explícita del autor en textos académicos. Rasal, 2, 31-44.

Gallardo, S. (2005a). Pragmatic support of medical recommendations in popularization texts. Journal of Pragmatics, 37(6), 813-835. 
Gallardo, S. (2005b). Los médicos recomiendan. Un estudio de las notas periodísticas sobre salud. Buenos Aires: Eudeba.

Gallardo, S. (2009). La estructura ilocutiva y la distinción entre géneros discursivos. En G. Ciapuscio (Ed.), De la palabra al texto. Estudios lingüísticos del español (pp.131-164). Buenos Aires: Eudeba.

Giannoni, D. S. (2006). Disciplinary and linguistic identities in the journal editorial genre. Paper presented at the Conference on Identity and Culture in English Domain-Specific Discourse, University of Naples, 19-20 October 2006. En G. Di Martino; V. Polese \& M. Solly (Eds.), Identity and culture in English domain specific discourse. Napoli: Edizioni Scientifiche Italiane. Disponible en: http://www.unibg.it/dati/persone/991/2701.pdf

Gras, P. \& García, M. A. (2010). La delimitación de la recomendación como acto de habla. En R. Caballero \& M. J. Pinar (Eds.), Modos y formas de la comunicación bumana (pp. 681-688). Cuenca: Publicaciones de la Universidad de Castilla-La Mancha.

Gülich, E. \& Kotschi, T. (1987). Les actes de reformulation dans la consultation La Dame de Caluire. En P. Bange (Ed.), L'analyse des interactions verbales. La Dame de Caluire: Une consultation (pp.15-81). Berne/ Frankfurt/ Nueva York/ París: Lang.

Gutiérrez, R. M. (2008). El género manual en las disciplinas académicas: Una caracterización desde el sistema de la obligación. Revista Signos. Estudios de Lingüística, 41(67), 177-202.

Gutiérrez, R. M. (2010). Especialización del discurso: Una caracterización desde el sistema de la obligación. Revista de Lingüistica Teórica y Aplicada, 48(1), 105-132.

Hyland, K. (1998). Persuasion and context: The pragmatics of academic metadiscourse. Journal of Pragmatics, 30, 437-455.

Hyland, K. (2002). Directives: Argument and engagement in Academic Writing. Applied Linguistics, 23(2), 215-39.

Hyland, K. (2005). Stance and engagement: A model of interaction in academic discourse. Discourse Studies, 7(2), 173-192.

Krippendorff, K. (1997). Metodología de análisis de contenido. Madrid: Paidós.

Lakoff, G. (1987). Women, fire and other dangerous things. Chicago: The University of Chicago Press. 
López Samaniego, A. \& Taranilla, R. (2012). Análisis contrastivo de la formulación de recomendaciones en dos géneros jurídicos. Ibérica, 23, 65-88.

Luukka, M. R. (1994). Metadiscourse in academic texts. En B. L. Gunnarsson, P. Livell \& B. Nordberg (Eds.), Text and Talk in Professional Contexts (pp. 77-88). Upsala: ASLA, The Swedish Association of Applied Linguistics.

Martínez-Flor, A. (2005). A theoretical review of the speech act of suggesting: Towards a taxonomy for its use in FLT. Revista Alicantina de Estudios Ingleses, 18, 167-187.

Montolío, E. \& López Samaniego, A. (2010). Especificidades discursivas de los textos profesionales frente a los textos académicos: El caso de la recomendación profesional. En G. Parodi (Ed.), Alfabetización académica y profesional en el Siglo XXI: Leer y escribir desde las disciplinas (pp. 215-245). Madrid: Planeta.

Mulder, G. (1993). ¿Por qué no coges el teléfono? Acerca de los actos de habla indirectos. Diálogos Hispánicos, 12, 181-208.

Mulder, G. (1998). Un estudio empírico de los actos de habla directivos en español. Diálogos hispánicos, 22, 237-276.

Nwogu, K. N. (1997). The medical research paper: Structure and functions. English for Specific Purposes, 16(2), 119-138.

Palmer, F. R. (1995). Modality and the English modals. Londres: Longman.

Pérez Hernández, L. (2001). Illocution and cognition: A constructional approach. Biblioteca de Investigación, 28. Logroño: Universidad de La Rioja.

Ridruejo, E. (1999). Modo y Modalidad. El modo en las subordinadas sustantivas. En I. Bosque \& V. Demonte (Eds.), Gramática Descriptiva de la Lengua Española, vol. 2 (pp. 3209-3251). Madrid: Espasa-Calpe.

Romanos de Tiratel, S. (2002). El editorial: Una opinión desde la trastienda. Información, Cultura y Sociedad, 7, 5-8.

Sabaj, O. \& González, C. (2013). Seis propósitos comunicativos del discurso del editor de las revistas científicas. DELT A, 29(1), 59-78.

Salager Meyer, F. (2002). Market-Place, Self-Confidence and Criticism in Medical Editorials. Revista Canaria de Estudios Ingleses, 44, 65-78.

Searle, J. (1975). Indirect speech acts. En P. Cole \& J. L. Morgan (Eds.), Syntax and Semantics, 3: Speech Acts (pp. 59-82). Nueva York: Academic Press.

Searle, J. (1979). Expression and meaning: Studies in the theory of speech acts. Cambridge, Londres, Nueva York, Melbourne: Cambridge University Press. 
Swales, J. (1990). Genre analysis. English in academic and research settings. Cambridge: Cambridge University Press.

Tang, R. \& John, S. (1999). The 'I' in identity: Exploring writer identity in student academic writing through the first person pronoun. English for Specific Purposes, 18, S23-S39.

Vázquez y del Árbol, E. (2005). A genre-based study of biomedical editorials and letters to the editor: a contrastive analysis. Ibérica, 10, 145-160.

Verstraete, J. C. (2001). Subjective and objective modality: Interpersonal and ideational functions in the English modal auxiliary system. Journal of Pragmatics, 33(10), 1505-1528.

Verstraete, J. C. (2005). Scalar quantity implicatures and the interpretation of modality. Problems in the deontic domain. Journal of Pragmatics, 37(9), 1401-1418.

\section{NOTAS}

1 "The term move means a text segment made up of a bundle of linguistic features (lexical meanings, propositional meanings, illocutionary forces, etc.) which give the segment a uniform orientation and signal the content of discourse in it. Each move is taken to embody a number of constituent elements or slots which combine in identifiable ways to constitute information in the move" (Nwogu, 1997: 122).

${ }^{2}$ Los modelos cognitivos idealizados, en términos de Lakoff, son entidades conceptuales, estructuradas, con las que organizamos nuestro conocimiento.

3 SciELO (Scientific Electronic Library Online) es una red de bibliotecas electrónicas conformada por colecciones de revistas científicas con acceso abierto, libre y gratuito.

${ }^{4}$ El destacado en negrita es nuestro. 